\title{
МЕХАНИЗМ ОРГАНИЗАЦИИ УПРАВЛЕНИЯ ХИМИЧЕСКИМИ ВЕЩЕСТВАМИ НА ПРОМЫШЛЕННЫХ ПРЕДПРИЯТИЯХ
}

\author{
(c) 2020 Табакова Анастасия Станиславовна \\ Санкт-Петербургский политехнический университет Петра Великого, Россия, Санкт-Петербург
}

\section{(c) 2020 Новикова Ольга Валентиновна}

Санкт-Петербургский политехнический университет Петра Великого, Россия, Санкт-Петербург

На современных промышленных предприятиях повсеместно присутствуют химические вещества, используемые для обслуживания оборудования и поддержания его базового состояния, а также для некоторых предприятий как сырье для производства конечного продукта. Однако, химические вещества могут нанести существенных вред окружающей среде и человеку, в связи с этим в России существует ряд требований к обращению с химическими веществами, а именно обязательная маркировка и наличие паспорта безопасности для химических веществ на предприятии [1], требования к хранению [2] и допустимые выбросы для промышленных предприятий [3]. Выполнение требований данных документов ведет к финансовым вложениям со стороны предприятий. В связи с этим актуально разработать единый механизм управления химическими веществами на предприятии, который будет учитывать все требования законодательства, а также позволит предприятиям сокращать потребление химических веществ, что снизит экологическое воздействие данных предприятий, а также позволит сократить затраты на закупку потребляемых химических веществ.

Ключевые слова: управление химическими веществами, промышленные предприятия, экологический менеджмент.

Цель: Разработать механизм организации управления химическими веществами на промышленных предприятиях для достижения минимальных экономических и экологических ущербов.

Объект: Промышленные предприятия, использующие химические вещества с целью обслуживания оборудования или производства конечного продукта.

Предмет: Управление химическими веществами на предприятии.

Задачи:

1. Исследование требований к обращению с химическими веществами в Российской Федерации.

2. На основе анализа требований разработать механизм организации управления химическими веществами, который также позволит снижать затраты промышленных предприятий на химические вещества.

3. Оценка экономического эффекта внедренного механизма.

Первоначальным документом, который необходимо изучить для работы с химическими веществами, является документ «ГОСТ 313402013 Предупредительная маркировка химической продукции. Общие требования», кото- рый соответствует рекомендациям ОOH ST/SG/ AC.10/30/Rev.4 «Globally Harmonized System of Classification and Labelling of Chemicals (GHS)» (Согласованная на глобальном уровне система классификации опасности и маркировки химической продукции (СГС)) [4]. Согласно данному документу каждое химическое вещество, находящееся на промышленном предприятии должно иметь предупредительную маркировку, которая должна включать идентификационные данные химической продукции (наименование и обозначение продукции, включая торговое наименование, данные о составе продукции и другие данные, позволяющие однозначно отличить конкретную химическую продукцию от прочей химической продукции, находящейся в обращении на рынке), сведения об организации (лице) - производителе или поставщике, включая наименование организации, адрес, контактные данные для экстренных обращений, описание опасности, включая знак опасности, сигнальное слово, краткую характеристику опасности, меры по предупреждению опасности, указание на то, что более полная информация по безопасному обращению химической продукции находится в паспорте безопасности.

Существующие классы опасности химиче- 
ских веществ и их пиктограммы представлены в Таблице 1.

ПОТ Р М-004-97 Межотраслевые правила по охране труда при использовании химических веществ [2] выдвигают требования к промыш- ленным предприятиям по хранению химических веществ. Описанные в документе требования представим в визуально удобном виде на Рисунке 1.

Допустимые выбросы для промышленных

\section{Таблица 1. Существующие классы опасности химических веществ и их пиктограммы}

\begin{tabular}{|l|l|}
\hline Пиктограмма & \multicolumn{1}{|c|}{ Описание } \\
\hline & опасные для здоровья человека \\
\hline & токсичные \\
\hline & взрывоопасные \\
\hline & око-токсичные \\
\hline & горючие \\
\hline & коррозионные вещества \\
\hline
\end{tabular}

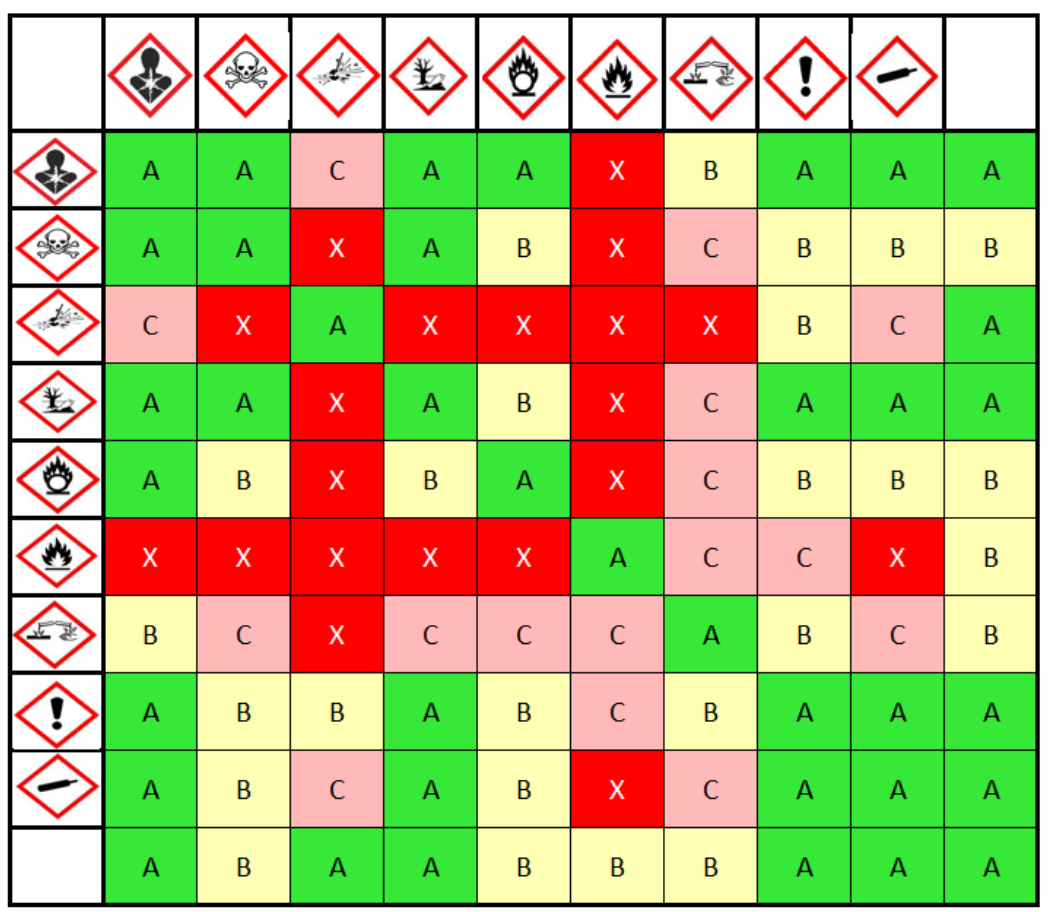

\begin{tabular}{|c|c|}
\hline X & $\begin{array}{c}\text { Субстанции и материалы, } \\
\text { которые должны храниться на } \\
\text { разных складах }\end{array}$ \\
\hline C & $\begin{array}{c}\text { суббстанции и материалы, } \\
\text { в разных частях склада, } \\
\text { разделенных противопожарной } \\
\text { В }\end{array}$ \\
\hline & $\begin{array}{c}\text { Субстанегородкой } \\
\text { располагаться в одном отсеке } \\
\text { склада. Дистанция между ними } \\
\text { должна быть не меньше 10 } \\
\text { метров }\end{array}$ \\
\hline A & $\begin{array}{c}\text { Субстанции и материалы могут } \\
\text { располагаться в одном отсеке } \\
\text { склада, дистанция не } \\
\text { специфицируется }\end{array}$ \\
\hline
\end{tabular}


предприятий регламентируются ГОСТ 17.2.3.022014 Правила установления допустимых выбросов загрязняющих веществ промышленными предприятиями. При этом для каждого субъекта Российской Федерации региональное Правительство выпускает дополнительное постановление, предписывающие допустимые выбросы с конкретными значениями. К примеру, в Санкт-Петербурге на основании Постановления Правительства Российской Федерации от 29.07.2013 № 644 для сточных вод предприятий введены предельно допустимые концентрации (ПДК) вредных веществ, превышение которых недопустимо.

С учетом требований вышеперечисленных документов необходимо разработать единый механизм, который будет позволять предприятиям также повышать экономическую эффективность.

Механизм представляет собой следующую последовательность действий:

1. Создать реестр всех химических веществ, включающий название химического вещества, класс опасности из паспорта безопасности материала, требования к обращению, упаковочную тару, в которой сырье приходит.

2. Внедрить подход по выставляемым требованиям к упаковке совместно с отделом закупок (Рис 2). При выборе тары необходимо преследовать цели снижения количества химических отходов, а именно доставлять химиче- ские вещества максимальными объемами, так как при этом будет оставаться меньше нерасходуемого остатка, а также снизится количество образуемого отхода упаковки. Однако, следует учитывать при этом, что складские мощности ограничены и в целях экономической эффективности количество хранимого материала на складе необходимо снижать. В связи с этим авторы рекомендуют привозить в цистернах те материалы, которые имеют самое большое потребление на предприятиях [6].

3. Внедрить подход к процессу появления новых химических веществ на предприятии (Рис 3). За необходимость изменение формулы и закупки новых химических веществ, а также за получение MSDS и спецификации по ним отвечает отдел научно-исследовательских разработок и отдел закупок. За анализ рисков с принятием решения о том, начинать ли использовать новое вещество на фабрике или нет отвечает отдел охраны труда (с целью убедиться, что требования к рабочему месту для нового вещества соответствуют существующим на производстве) и отдел охраны окружающей среды (с целью убедиться, что вещество по маркировке соответствует требованиям по снижению рисков и экологической нагрузки фабрики, а также не приведет к рискам в обращении). В случае, если принято решение начать использовать вещество на предприятии, то далее отдел охраны труда и окружающей среды вносит вещество в базу данных химических

\section{Упаковка хим. вещества}

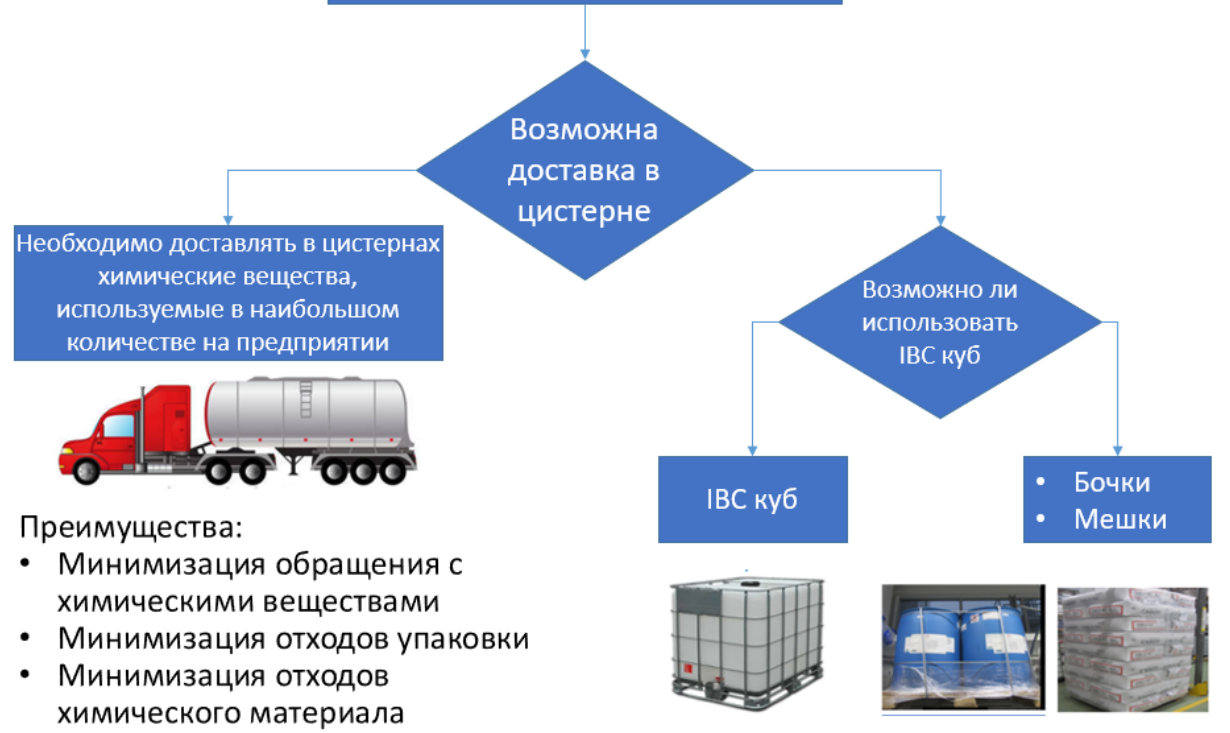

Puc. 2. Необходимые требования к упаковке химических веществ 


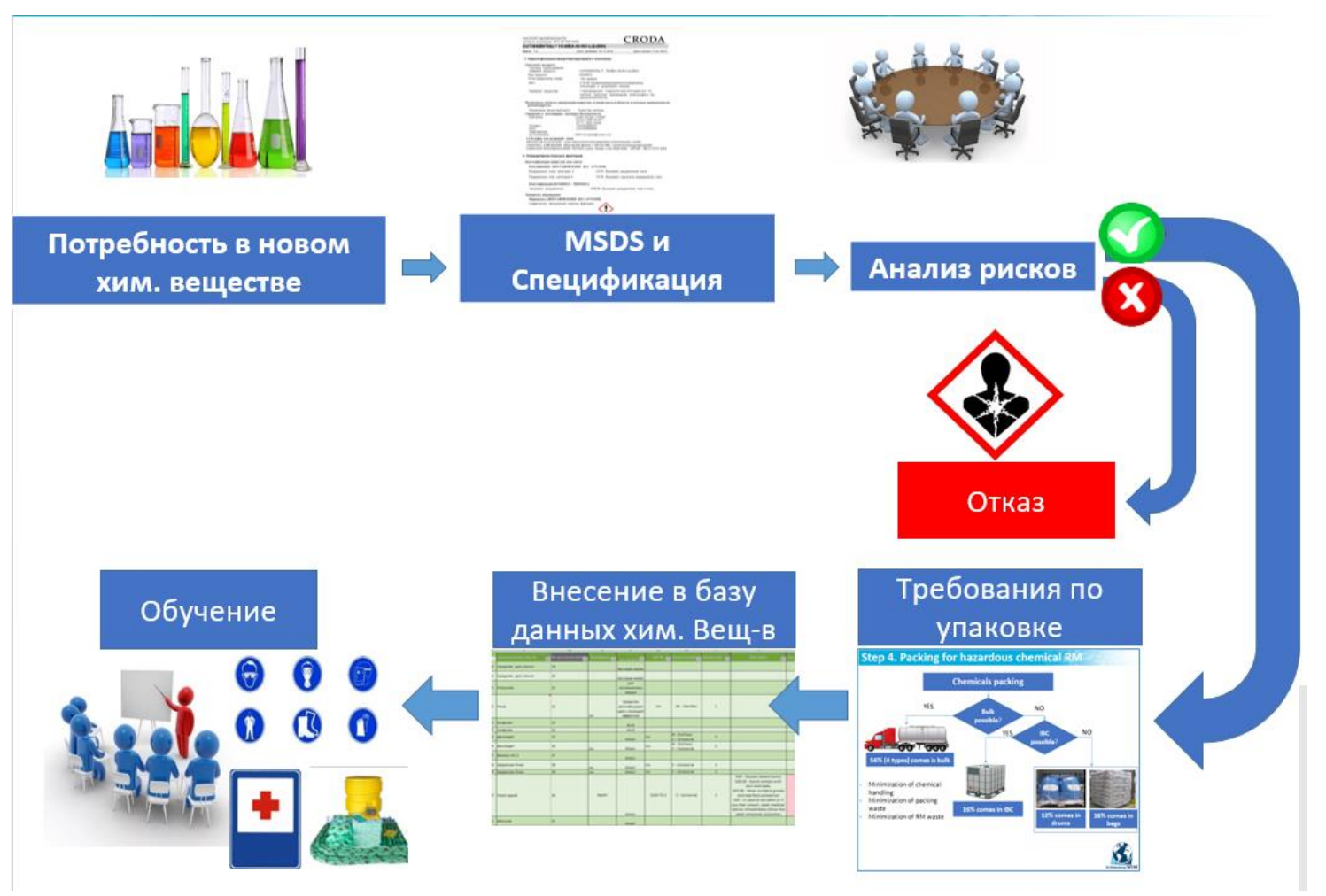

Рис 3. Подход к процессу появления новых химических веществ на предприятии

веществ и проводит обучение с персоналом, который будет использовать данное вещество. При этом необходимо учитывать введенные на предприятии требования по упаковке химических веществ (рис 2).

4. Внедрение единого подхода к управлению химическими веществами на предприятии (Табл. 2).

5. Далее необходимо начать сокращение потребления количества (массы) веществ. Осуществлять данные активности также необходимо согласно приоритетам пирамиды опасности химических веществ (Рис 4) [1], то есть сначала атаковать верхние вещества постепенно передвигаясь вниз по пирамиде. Информацию о потерях материалов после предыдущего этапа можно будет почерпнуть у аналитического отдела.

На основании практического опыта на промышленном предприятии авторы предлагают разделение потерь на 6 типов:

1. Ненужное потребление - потребление, которое не приводит к производству продукции (утечки, поломки и т.д.).

2. Избыточное потребление - Потребление, которое варьируется при одинаковой операции.
3. Недостаточная оптимизация - устаревшее оборудование.

4. Не использование возобновляемых ресурсов - продукт который можно повторно использовать подвергается утилизации.

5. Потери по перемещениям - потери, которые невозможно устранить даже с более новым оборудованием.

6. Инвентарные потери - потери, связанные с неправильным хранением.

Контрмеры, показавшие применимость для промышленного предприятия в СанктПетербурге представлены в Табл. 3.

Данный подход показал свою применимость на промышленном предприятии в СанктПетербурге, где за год удалось снизить потребление химических веществ на тонну производимой продукции на $4 \%$, что в денежном эквиваленте составило 350 тысяч Евро экономии в год.

Согласно Федеральной службы государственной статистики за последние 3 года количество образуемых отходов на предприятиях химической промышленности составляет порядка 9,8\% от общего объема производства за год [7]. Опыт авторов в рамках работы на промышленных предприятиях показывает, что для предприятий, где более 5\% сырья составляют хи- 
Таблица 2. Подход к управлению химическими веществами на предприятии.

\begin{tabular}{|c|c|c|}
\hline Процесс & Ответственный & Набор задач \\
\hline $\begin{array}{l}\text { Составление плана } \\
\text { производства }\end{array}$ & Плановый отдел & $\begin{array}{l}\text { Определение спроса покупателей продукции в соответ- } \\
\text { ствии с принятым на предприятии горизонтом планиро- } \\
\text { вания }\end{array}$ \\
\hline Выбор поставщика & Отдел закупок & $\begin{array}{l}\text { Для того, чтобы закупить необходимый материал перво- } \\
\text { начально необходимо провести тендер и выбрать постав- } \\
\text { щика, который соответствует внутренним требованиям } \\
\text { промышленного предприятия, готов предоставлять каче- } \\
\text { ственную продукцию в необходимые сроки, а также имеет } \\
\text { наиболее выгодные экономические условия. После этого } \\
\text { составляется контракт с данным поставщиком. }\end{array}$ \\
\hline Закупка материалов & Плановый отдел & $\begin{array}{l}\text { В соответствии с планом производства и согласованном } \\
\text { на предприятии количеством дней хранения материалов } \\
\text { на складе необходимо определить материалы, их количе- } \\
\text { ства и даты поставки. }\end{array}$ \\
\hline $\begin{array}{l}\text { Транспортировка } \\
\text { материалов }\end{array}$ & Поставщик & $\begin{array}{l}\text { Необходимо, чтобы поставщик при перемещении продук- } \\
\text { ции имел паспорта безопасности химических веществ. }\end{array}$ \\
\hline Контроль при въезде & Служба безопасности & $\begin{array}{l}\text { Служба безопасности должна проверить наличие заказа } \\
\text { на материал в файле предоставляемом отделом планиро- } \\
\text { вания и далее убедиться, что машина привезла материалы } \\
\text { без видимых повреждений, а также сама в исправном со- } \\
\text { стоянии и не имеет течи масла, чтобы не допустить эколо- } \\
\text { гического загрязнения внутренней территории фабрики. }\end{array}$ \\
\hline $\begin{array}{l}\text { Логистика на пред- } \\
\text { приятии }\end{array}$ & Логистический отдел & $\begin{array}{l}\text { Логистический отдел должен осуществлять прозрачное } \\
\text { перемещение материалов по фабрике за счет четкого } \\
\text { учета количества привозимых материалов поставщиком, } \\
\text { хранимых материалов, отправленных в производство, } \\
\text { хранимое количество готовой продукции и отгруженное } \\
\text { количество готовой продукции покупателям. }\end{array}$ \\
\hline Хранение & $\begin{array}{l}\text { ООТиОС, логистический } \\
\text { отдел }\end{array}$ & $\begin{array}{l}\text { Необходимо убедиться, что выполняются все требования } \\
\text { хранения сырья и готовой продукции [2]. }\end{array}$ \\
\hline $\begin{array}{l}\text { Определение потерь } \\
\text { химических веществ }\end{array}$ & $\begin{array}{l}\text { Аналитический отдел и } \\
\text { производственный отдел }\end{array}$ & $\begin{array}{l}\text { Аналитический отдел фиксирует потери из системы, } \\
\text { которой пользуется логистический и плановый отделы на } \\
\text { каждом этапе перемещения химических веществ на фа- } \\
\text { брике. Производственный отдел организует дополнитель- } \\
\text { ные точки сбора статистики в точках образования отходов } \\
\text { с целью более простого определения корневой причины } \\
\text { потери. }\end{array}$ \\
\hline
\end{tabular}

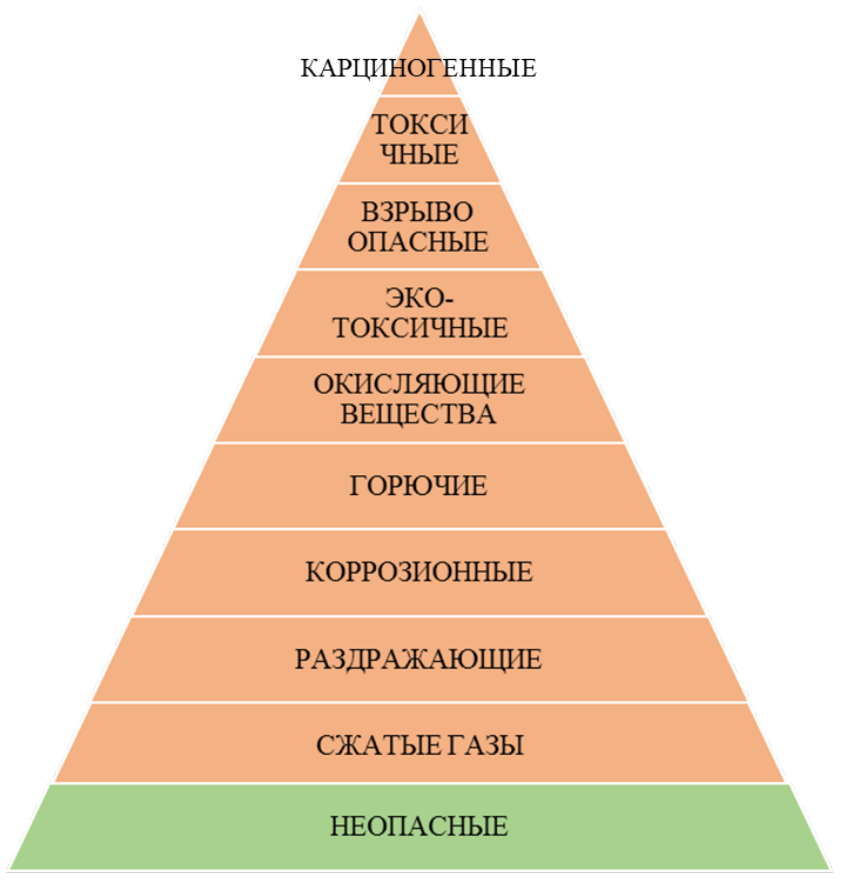

Рис 4. Пирамида опасности химических веществ 
Таблица 3. Потери и предлагаемые для их устранения контрмеры

\begin{tabular}{|c|c|}
\hline Тип потери & Контрмеры \\
\hline Ненужное потребление & $\begin{array}{l}\text { 1. Необходимо определять причину каждой поломки и протечки и устранять } \\
\text { причины их появления, с целью не допустить повтора. } \\
\text { 2. Сокращать количество нескачиваемого остатка в таре с веществами. К при- } \\
\text { меру, система, переворачивающая бочки. } \\
\text { 3. Изменить тару сырья совместно с отделом закупок на ту, которая имеет мень- } \\
\text { ше нескачиваемого остатка. }\end{array}$ \\
\hline Избыточное потребление & Часто связана с людьми. Необходимо провести обучение персонала. \\
\hline $\begin{array}{l}\text { Недостаточная } \\
\text { оптимизация }\end{array}$ & $\begin{array}{l}\text { При допустимой для предприятия окупаемости необходимо заменить оборудо- } \\
\text { вание. }\end{array}$ \\
\hline $\begin{array}{l}\text { Не использование возоб- } \\
\text { новляемых ресурсов }\end{array}$ & $\begin{array}{l}\text { 1. Связано с человеческими ошибками - требуется обучение } \\
\text { 2. Требования качества приводят к утилизации материалов. Поиск совместно- } \\
\text { го решения с отделом качества по безопасному использованию материалов. К } \\
\text { примеру, системы продавливания в трубопроводах. }\end{array}$ \\
\hline Потери по перемещениям & $\begin{array}{l}\text { На данный момент фиксируются и необходимо регулярно мониторить рынок } \\
\text { современных технологий на предмет появления технологии, позволяющей } \\
\text { атаковать одну из потерь. }\end{array}$ \\
\hline Инвентарные потери & $\begin{array}{l}\text { Работа с плановым отделом по более четкому планированию сырья и материа- } \\
\text { лов с целью не допустить истечения срока годности. }\end{array}$ \\
\hline
\end{tabular}

мические вещества потери химических веществ составляют примерно 10\% от произведенной продукции. Таким образом, внедряя механизм организации управления химическими веществами, предприятия смогут не только выполнить требования нормативных документов, но и достигнуть экономического эффекта за счет сокращения потребления химических веществ на тонну производимой прожукции. Апробация данного подхода на промышленном предприятии в Санкт-Петербурге показала, что данный механизм можно внедрить за полгода.

\section{Библиографический список}

1. ГОСТ 31340-2013 Предупредительная маркировка химической продукции. Общие требования http://docs. cntd.ru/document/1200107846

2. ПОТ Р M-004-97 Межотраслевые правила по охране труда при использовании химических веществ https:// dpvolga.ru/pravila-hraneniya-himicheskih-veshhestv/

3. ГОСТ 17.2.3.02-2014 Правила установления допустимых выбросов загрязняющих веществ промышленными предприятиями

4. ST/SG/AC.10/30/Rev.4 «Globally Harmonized System of Classification and Labelling of Chemicals (GHS)

5. Постановление Правительства Российской Федерации от 29.07.2013 № 644 для сточных вод предприятий введены предельно допустимые концентрации (ПДК) вредных веществ, превышение которых недопустимо.

6. http://www.garant.ru/products/ipo/prime/doc/12081564/

7. https://www.gks.ru/folder/11194 